\title{
Como escrever a História?
}

Cecilia Helena de Salles Oliveira

A Historiografia, como observou Michel de Certeau, traz no próprio nome o paradoxo das mediações entre "história" e "escrita". Refletir sobre o discurso por meio do qual tempo e história se revestem de inteligibilidade significa debruçar-se sobre problemas de método que preocuparam e ainda preocupam os historiadores. No início do século $\mathrm{XX}$, essas questões articularam-se ao delineamento e à qualificação de campo específico de conhecimento, sendo acompanhadas, naquele momento, pela crítica à história-memória nacional que havia marcado o século XIX. Desde então, de modo recorrente e por intermédio de vertentes teóricas diferentes, os historiadores não cessaram de interrogar os procedimentos de "fazer a história", perscrutando o lugar de produção do saber histórico, as práticas que o disciplinam e a construção das narrativas que o registram e divulgam.

É possível tomar como marcos desse intenso embate contribuições legadas por Lucien Febvre e Walter Benjamin. A despeito das particularidades de suas obras e dos percursos divergentes que traçaram, ambos sublinharam a intervenção do historiador na fabricação e seleção dos "fatos" e o peso do presente na definição das formas a partir das quais o passado seria interrogado. Alertaram, também, para as implicações históricas e políticas da "convicção realista", segundo a qual passado e história seriam um banco de dados à disposição do analista que, munido de objetividade e imparcialidade, poderia descrevê-los e deles se apropriar. Voltaram-se, assim, para diversas ordens de questionamento: as relações do historiador com suas fontes; as mediações pela quais temas e problemas são recortados e investigados; e, de modo especial, tradições historiográficas que ora conduzem à repetição do saber consagrado pela história-memória nacional ora promovem a identificação do presente com o passado que se pretende compreender, realimentando sob formulações aparentemente inovadoras pressupostos que se supõem abandonados.

Essas questões foram reformuladas e assumiram novos contornos, nas décadas de 1970 e 1980, por intermédio, entre outras, das obras de Jacques Le Goff e Michel de Certeau. Destaque particular merecem os cinco monumentais volumes de Les lieux de mémoire, coletânea dirigida por Pierre Nora e que reuniu estudos destinados a inventariar e reconstituir os fundamentos políticos, intelectuais e institucionais da história da nação francesa, cujo marco inaugural foi a Revolução de 1789. No momento em que se prepararam as celebrações dos duzentos anos da Revolução, uma das propostas em pauta foi a de discutir as condições de produção de uma nova história nacional, contraposta àquela do século XIX. O conceito de "lugar de memória", elaborado na dupla acepção de instrumento de investigação e categoria histórica, surge como estratégia para avaliar a probabilidade de uma escrita da história da nação, capaz de fazer face às exigências acadêmicas da História e às demandas geradas pela experiência de um tempo acelerado, assinalado por contraditórias vinculações entre obsolescência e museificação, en- 
tre memorização e esgarçamento de vestígios materiais e culturais.

Em concomitância a esses esforços, e na mesma época, professores e pesquisadores brasileiros também concentravam atenções nos fundamentos do ofício e em sua profissionalização. A criação, nos anos 1930, dos primeiros cursos superiores de História, em São Paulo (1934) e no Rio de Janeiro (1935), permitiu que a pesquisa e a transmissão de conhecimentos nessa área fossem deslocadas dos Institutos Históricos para outros centros, o que trouxe implicações importantes do ponto de vista da escrita e dos conteúdos abordados. Na década de 1970, com a institucionalização de programas de pós-graduação, na Universidade de São Paulo (1971), na Universidade Federal Fluminense (1971) e na Universidade Estadual de Campinas (1976), contribuições inovadoras avivaram ainda mais o debate em torno dos nexos entre história e escrita da História.

Ainda hoje encontra repercussão a instigante pergunta lançada, em 1982, por Carlos Alberto Vesentini na tese de doutoramento, intitulada $A$ teia do fato: "Com que critério um historiador fala das lutas e agentes de uma época que não é a sua?". Ao frisar a profundidade da interrogação, dada a força com a qual episódios consagrados pela memória projetavam-se no presente e sobre quem exercia o ofício de historiar, Vesentini problematizava não apenas o lugar do historiador nas tramas que entrelaçavam, mas, ao mesmo tempo, diferenciavam presente e passado. Indagava-se sobre os fundamentos da prática historiográfica e sobre as tradições que, no Brasil, cercavam a construção do conhecimento histórico.

É no âmbito dessa discussão que se situa a coletânea organizada por Manoel Luiz Salgado Guimarães. Fruto de evento de natureza acadêmica, realizado em outubro de 2005 e promovido pelo Programa de Pós-Graduação em História Social da Universidade Federal do Rio de Janeiro, a obra reúne o texto da conferência de abertura, "Tempos do mundo, história, escrita da História", proferida por François Hartog, e doze artigos distribuídos em três núcleos temáticos - "Uma 'retórica da nacionalidade': a escrita da História no século XIX"; "Sociabilidades letradas"; e "Tradições e linguagem".

Dedicado a especialistas e alunos de cursos de História, o livro apresenta resultados de pesquisas acadêmicas, em diferentes estágios de desenvolvimento. Procura aliar contribuições de historiadores reconhecidos e textos produzidos por pós-graduandos no nível de doutorado, possibilitando igualmente o contato do leitor com renomado historiador francês que, nos últimos anos, por meio de vasta produção, tem aprofundado estudos sobre a escrita da História entre os antigos e sobre os modos pelos quais, a partir do século XVIII, alteraram-se concepções e narrativas da história e sobre a História.

Infelizmente, porém, os limites de uma conferência impedem que se perceba com clareza a complexidade das reflexões e argumentos propostos por Hartog, em especial as abrangentes implicações historiográficas da noção de "regime de historicidade" e sua inserção em campo de discussão que remete à obra de Reinhart Koselleck. Para o leitor interessado em ampliar referências - o que nesse caso é aconselhável -, foram traduzidos para o português alguns dos livros do autor, a exemplo, entre outros, 
de O século XIX e a História: o caso Fustel de Coulanges (Editora da UFRJ, 2003) e $O$ s antigos, o passado e o presente (UnB, 2003).

A despeito das singularidades que caracterizam cada um dos artigos, há entre eles alguns problemas de fundo que permitem articulá-los não só do ponto de vista dos objetivos mais gerais, como em termos dos referenciais nos quais estão firmados. A questão central diz respeito ao reconhecimento de que para compreender a escrita da História do Brasil e no Brasil é preciso realizar um amplo trabalho de investigação e reconstituição de fontes e lugares de produção do conhecimento histórico, a começar pelo Instituto Histórico e Geográfico Brasileiro, fundado em 1838. Nesse sentido, poder-se-ia considerar que a inspiração para essa empreitada adveio da problematização da famosa pergunta "Como se deve escrever a história do Brasil?”, que Karl von Martius, por meio da Revista do Instituto, se dispôs a encaminhar, em 1844. Compreender os significados do plano e das justificativas apresentadas pelo naturalista representa descobrir e interrogar outras propostas da mesma natureza, mas com conteúdo diverso, discutidas pelos sócios da instituição desde sua instalação oficial. Representa, também, reconstituir por quais modos, em meio ao processo de Independência e de configuração do Império do Brasil na primeira metade do século XIX, projetavam-se discursos sobre a história da nação e práticas concernentes à organização física e à identificação de registros que deliberadamente deveriam ser preservados, constituindo-se assim um campo de estudos e, ao mesmo tempo, a figura daquele que teria a tarefa de historiar.
A perspectiva de pontuar e traçar os momentos de fundação da escrita da História nacional do século XIX evidencia-se no artigo de Manoel Luiz Salgado Guimarães "Entre as luzes e o romantismo: as tensões da escrita da História no Brasil oitocentista". Aqui se discutem, entre outros aspectos, as linhas de continuidade e ruptura entre o lugar destinado à História na cultura iluminista e enciclopédica do século XVIII e a configuração da disciplina da História no século XIX.

A mesma perspectiva de refazer o território da História, construído aos poucos e por vezes de forma errática, está, porém, presente no tratamento dispensado a alguns dos protagonistas centrais desse "fazer" no século XIX e início do $\mathrm{XX}$, e que auxiliaram na institucionalização da disciplina. Três dos artigos debruçaram-se sobre a trajetória e a obra construída por Varnhagen, merecendo atenção especial as considerações de Temístocles Cezar acerca da tese que Varnhagen elaborou, nos anos 1870, sobre a origem dos índios brasileiros. O historiador, contrariando argumentos indianistas, buscou por meio de estudos lingüísticos comprovar que os tupis eram selvagens e descendiam de povos do antigo Egito. Também mereceram artigos específicos Euclides da Cunha, Gilberto Freyre e Capistrano de Abreu. No caso de Capistrano, sua atuação foi analisada não apenas como historiador, mas na função que desempenhou na Biblioteca Nacional e no âmbito da leitura e edição crítica de fontes, o "gesto inaugural da operação historiográfica", como observou a autora do artigo, Maria das Graças de Oliveira.

Muito embora predominem na coletânea pesquisas sobre o século XIX, há 


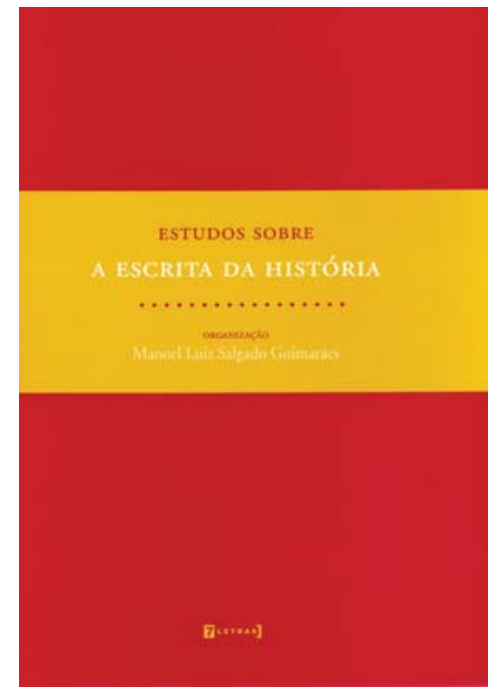

GUIMARÃES, Manoel Luiz Salgado (Org.) Estudos sobre a escrita da História. Apresentação de Carlos Fico. Rio de Janeiro: 7Letras, 2006. 265p.

dois estudos que se ocupam de fontes e problemas relacionados à escrita da História e às condições de produção do saber histórico no século XX. Marieta de Moraes Ferreira trata do surgimento dos cursos universitários de História no Rio de Janeiro, procurando investigar as relações entre ensino, concepções de História e a institucionalização de lugares para a produção do conhecimento histórico, diferentes do Instituto Histórico. Já o artigo de Lúcia Maria Paschoal Guimarães analisa os participantes e os trabalhos apresentados em dois congressos de História nacional, realizados no Rio de Janeiro, respectivamente, em 1914 e 1949, considerados eventos primordiais para a compreensão da historiografia brasileira na primeira metade do século passado.

Como em obras de natureza similar, também aqui existem diferenciações de profundidade entre os artigos, mas não de forma a comprometer o resultado final. Trata-se de conjunto de reflexões que propõe encaminhamentos enriquecedores para o entendimento histórico do movimento político e cultural no qual se engendrou uma escrita da História no Brasil. Mas, talvez, sua maior importância esteja no fato de provocar interrogações sobre os fundamentos do trabalho do historiador no passado e no presente, inventariando e problematizando práticas, concepções e instituições que fundamentaram - e em muitos casos ainda fundamentam - o ofício de historiar. Boa oportunidade para examinar, como sugeriu Vesentini, a "teia" que entrelaça o historiador, o movimento da história e a historiografia.

Cecilia Helena de Salles Oliveira é professora do Museu Paulista da USP e do Programa de Pós-Graduação em História Social da FFLCH/USP. Pesquisadora do CNPq. @-psalles@usp.br 